\title{
A RETROSPECTIVE STUDY ON ACCEPTABILITY AND COMPLICATIONS OF PPIUCD INSERTION
}

\author{
Runjun Doley¹, Bornali Pegu²
}

${ }^{1}$ Assistant Professor, Department of Obstetrics \& Gynaecology, Jorhat Medical College \& Hospital, Jorhat, Assam. ${ }^{2}$ Registrar, Department of Obstetrics \& Gynaecology, Jorhat Medical College \& Hospital, Jorhat, Assam.

\section{ABSTRACT}

\section{BACKGROUND}

Purpose: To study the acceptance level of Post-Partum Intrauterine Contraceptive Device (PPIUCD) insertion among women attending tertiary level hospital for delivery between January 2013 to July 2015 in relation to age, parity and mode of delivery, safety and their complaints/complications during followup visit.

\section{METHOD}

This is a retrospective study done in a tertiary care centre, Jorhat Medical College and Hospital, Assam, between January 2013 to July 2015. Women who had accepted PPIUCD after delivery (Vaginally or by Lower Segment Caesarean section) were included in this study. The entire PPIUCD inserted patients were followed up to 6 weeks and 6 months after delivery. With the help of data collected, relevant parameters and data are critically analysed in our study.

\section{RESULTS}

Acceptance of PPIUCD showed an increasing trend, acceptance was more among patients undergoing caesarean section; $43.86 \%$ of the acceptors were in the age group of 21-25 years. More than 50\% of the total acceptors in the study came for followup. The main complaints at followup were missing thread and bleeding. The main causes of removal were bleeding and pressure from family.

\section{CONCLUSION}

The acceptance of PPIUCD was high in this study. The PPIUCD was demonstrably safe having no serious complication reported after insertion or during followup and low rates of expulsion. The method may be particularly beneficial in our setting where women do not come for postnatal contraception counselling and usage.

\section{KEYWORDS \\ PPIUCD, LSCS,}

HOW TO CITE THIS ARTICLE: Doley R, Pegu B. A retrospective study on acceptability and complications of PPIUCD insertion. J. Evolution Med. Dent. Sci. 2016;5(31):1631-1634, DOI: 10.14260/jemds/2016/384

\begin{abstract}
INTRODUCTION
Intrauterine Contraceptive Devices (IUCDs) have been used by women in India for decades for spacing pregnancies and it is the most commonly used reversible method of contraception worldwide with about 127 million current users.[1] Approximately 27\% of births in India occur in less than 24 months after a previous birth, another $34 \%$ of births occur between 24 and 35 months; $61 \%$ of births in India occur at intervals that are shorter than the recommended birth-to-birth interval of approximately 36 months.[2] Immediate postpartum period is an ideal time to educate and counsel a woman on exclusive breast feeding, future fertility, birth spacing or limiting intentions and provision of appropriate family planning methods like IUCD and permanent sterilization.[2] India is the first country in the world to adopt an official population policy and launch official family planning programme way back in 1952, which remains the mainstay of family planning efforts.
\end{abstract}

Financial or Other, Competing Interest: None.

Submission 16-03-2016, Peer Review 29-03-2016,

Acceptance 31-03-2016, Published 16-04-2016.

Corresponding Author:

Dr. Runjun Doley,

Assistant Professor,

Department of Obstetrics \& Gynaecology,

Jorhat Medical College \& Hospital,

Jorhat-785001, Assam.

E-mail: drrunjundoley@rediffmail.com

DOI: $10.14260 /$ jemds $/ 2016 / 384$
However, universal adaptation of small family norm still remains a distant dream in India. Contraception practice in India is known to be skewed towards terminal methods, which means that contraception in India is practiced primarily for birth limitation rather than birth planning. [3] Family planning can avert nearly one-third of maternal deaths and $10 \%$ of child mortality when couples space their pregnancies more than two years apart.[4]

Studies show that pregnancies taking place within 24 months of previous birth have a higher risk of adverse outcome like abortions, preterm labour, postpartum haemorrhage, low birth weight babies, fetal loss and maternal death.[5] Since the introduction of Janani Shishu Suraksha Karyakaram (JSSK) and Janani Suraksha Yujana (JSY), the number of institutional deliveries have increased. Labour room is attended by large number of beneficiaries every day, Delivery provides a convenient opportunity for the woman to receive IUD services.

\section{MATERIALS AND METHODS}

This is a retrospective study carried out in the Department of Obstetrics and Gynaecology, Jorhat Medical College and Hospital, a tertiary care hospital in upper Assam, from $1^{\text {st }}$ January 2013 to $31^{\text {st }}$ July 2015. 


\section{OBJECTIVES}

1. To determine the proportion of woman who had accepted the Post-Partum Intrauterine Contraceptive Device (PPIUCD) insertion in relation to age, parity and mode of delivery.

2. To determine the safety of PPIUCD insertion.

3. To determine the complications/complaints of immediate PPIUCD insertion among patients who had accepted the device.

\section{Inclusion Criteria}

Woman who had accepted immediate postpartum (After removal of placenta) IUD insertion following delivery (Vaginally or by Lower Segment Caesarean Section).

\section{Exclusion Criteria}

Woman who had not accepted the PPIUCD insertion.

\section{RESULTS}

During the study period, $1^{\text {st }}$ January 2013 to $31^{\text {st }}$ July 2015 , total number of PPIUCD acceptance was 1217 out of 3320 counselled patients, of which $43.86 \%$ were in the age group of $21-25$ years followed by $37.95 \%$ acceptors in the age group of $<20$ years (Table 1). Maximum acceptance was observed among multipara (39.32\%). Of the total acceptance, $77.07 \%$ patients accepted PPIUCD during caesarean delivery while 22.93\% patients accepted PPIUCD following vaginal delivery (Table 2).

Out of 1217 patients (Total accepted), 278 did not come for followup. Of the 939 followed up patients, 314 had complications/complaints. It was observed that $12.35 \%$ had irregular bleeding, $15.12 \%$ had missed thread, $3.09 \%$ and $0.75 \%$ had expulsion and infection respectively and $2.13 \%$ had pain abdomen (Table 3). Highest rate of expulsion $(1.60 \%)$ was seen in between 7 days to 6 weeks of PPIUCD insertion and was lowest after 6 weeks of insertion $(0.53 \%)$ (Table 4). In $42.11 \%$ recipients, PPIUCD were removed due to bleeding followed by pressure from family (17.54\%) (Table 4). The continuation rate was $90.84 \%$ and failure rate was $0.11 \%$ (Table 5).

\section{DISCUSSION}

According to a report released by WHO in 2006, better family planning and birth spacing services resulted in better maternal and neonatal outcome. When promoted in countries with high birth rates, $32 \%$ of all maternal deaths and over one million deaths of children under five could be prevented. Healthy timing and spacing of pregnancies have a positive effect on maternal health and new born outcomes. ${ }^{[6]}$

The IUD is more effective than oral contraceptives at preventing pregnancy and it is reversible. Once it is removed, fertility returns. (Studies have found no adverse effects on fertility with the current IUDs.).[7]

- Unlike the pill, there is no daily routine to follow.

- Unlike the barrier methods (Spermicides, diaphragm, cervical cap and the male or female condom), there is no insertion procedure to cope with before or during sex.
- Intercourse can resume at any time and as long as the IUD is properly positioned, neither the user nor her partner typically feels the IUD or its strings during sexual activity.

- It is the least expensive form of contraception over the long term.

In our study, the total acceptance was 1217 out of 3320 counselled (36.66\%). Highest rate of acceptance was among age group of 21-25 yrs. (43.86\%), which is comparable with other studies done by Katheki G et al.[8] and Mishra S.[9] whereas in a study by Maluchuru S et al.[10] from Guntur, the highest rate of acceptance was among age group of 30-39 years $(27.67 \%)$. In our study, the acceptance was higher $(39.32 \%)$ in multipara as compared to primipara (33.10\%).

Similar observation was found in a study in North India, by Shukhla $\mathrm{M}$ et al.[5] where the acceptance was higher in multipara (68.33\%). Studies by Grimes et al.[11] and Borthakur $\mathrm{S}$ et al.[12] GMCH Assam also found higher acceptance among multipara. Goswami G et al.[13] also found higher acceptance (48\%) among multipara, whereas Maluchuru S et al.[10] Mishra S.[9] Gautam R et al.[14] and Vidyarama $\mathrm{R}$ et al.[15] found a higher acceptance in primipara which were $15.42 \%, 13.76 \%, 71.91 \%$ and $15.47 \%$ respectively.

In our study, the acceptance among LSCS patients and vaginally delivered patients were $77.07 \%$ and $22.93 \%$ respectively. This was similar to observations by Gautam R et al.[14] (LSCS-36.09\%, NVD-11.33\%) and Jairaj $S$ et al.[16] Telangana (LSCS-43.9\%, NVD-6.3\%). Borthakur S et al.[12] found more than $50 \%$ acceptors among patients undergoing caesarean section. In our study, missing thread was the most common complication (15.12\%). It is similar to Maluchuru S et al.[10] (16\%), whereas Mishra S.[9] and Gautam R et al.[14] found bleeding to be the most common complication in their study, which were $23.5 \%$ and $19 \%$ respectively. In a study in Central India by Kanhere AV et al. expulsion was the most common complication (22\%).

In our study, the most common reason for removal was bleeding $(42.11 \%)$ followed by pressure from family $(17.54 \%) ; 15.79 \%$ had removal due to changes in the menstrual cycle and pain abdomen. Only $8.77 \%$ had removal due to string problems. Maluchuru S et al.[10] found bleeding $(27.27 \%)$ and pressure from family $(27.27 \%)$ to be the most common reasons for removal.

Similar observation was by Mishra S. ${ }^{[9]}$ where bleeding (32.56\%) also was the most common reason for removal. In a study by Goswami G et al.[13] the significant reason for IUCD removal was pressure from husband and other family members. In our study, the highest expulsion $(1.60 \%)$ was seen in between 7 days to 6 weeks of insertion of PPIUCD. Similar observations were found by Maluchuru S et al.[10] and Mishra S.[9] where the highest expulsion was in between 7 days and 4 weeks, which were $2.5 \%$ and $7.60 \%$ respectively. In our study, we found only one case of intrauterine pregnancy out of 939 followed up patients. This was similar to a study by Kanhere AV et al.[17] where there was one case of intrauterine pregnancy out of 52 followed up patients. 


\begin{tabular}{|c|c|c|c|c|c|}
\hline Age & Total Counselled & Accepted & Percentage & Declined & Percentage \\
\hline$<20$ years & 1270 & 482 & 37.95 & 788 & 62.05 \\
\hline 21-25 years & 725 & 318 & 43.86 & 407 & 56.14 \\
\hline 26-30 years & 923 & 307 & 33.26 & 616 & 66.73 \\
\hline 31-35 years & 302 & 85 & 28.15 & 217 & 71.85 \\
\hline >36 years & 100 & 25 & 25 & 75 & 75 \\
\hline Total & 3320 & 1217 & & 2103 & \\
\hline \multicolumn{7}{|c|}{ Acceptance of PPIUCD in Relation to Parity } \\
\hline Primi & 1420 & 370 & $33.10 \%$ & 950 & $66.90 \%$ \\
\hline Multi & 1900 & 747 & $39.32 \%$ & 1153 & $60.68 \%$ \\
\hline Total & 3320 & 1217 & \\
\hline
\end{tabular}

\begin{tabular}{|c|c|c|}
\hline Mode of Delivery & Number & Percentage \\
\hline LSCS & 938 & $77.07 \%$ \\
\hline NVD & 279 & $22.93 \%$ \\
\hline Total & 1217 & \\
\hline \multicolumn{2}{|r|}{ Table 2: Acceptance of PPIUCD } \\
in Relation to Mode of Delivery \\
\hline
\end{tabular}

\begin{tabular}{|c|c|c|}
\hline $\begin{array}{l}\text { Complications } \\
\text { /Complaints }\end{array}$ & Number & Percentage \\
\hline Irregular bleeding & 116 & 12.35 \\
\hline Missed thread & 142 & $15.12 \%$ \\
\hline Infection & 7 & 0.75 \\
\hline Expulsion & 29 & $3.09 \%$ \\
\hline Uterine perforation & 0 & 0 \\
\hline Pain abdomen & 20 & $2.13 \%$ \\
\hline Total & 314 & \\
\hline \multicolumn{3}{|c|}{$\begin{array}{c}\text { Table 3: Complications/Complaints among } \\
\text { Recipients of PPIUCD at } 6 \text { Weeks }\end{array}$} \\
\hline
\end{tabular}

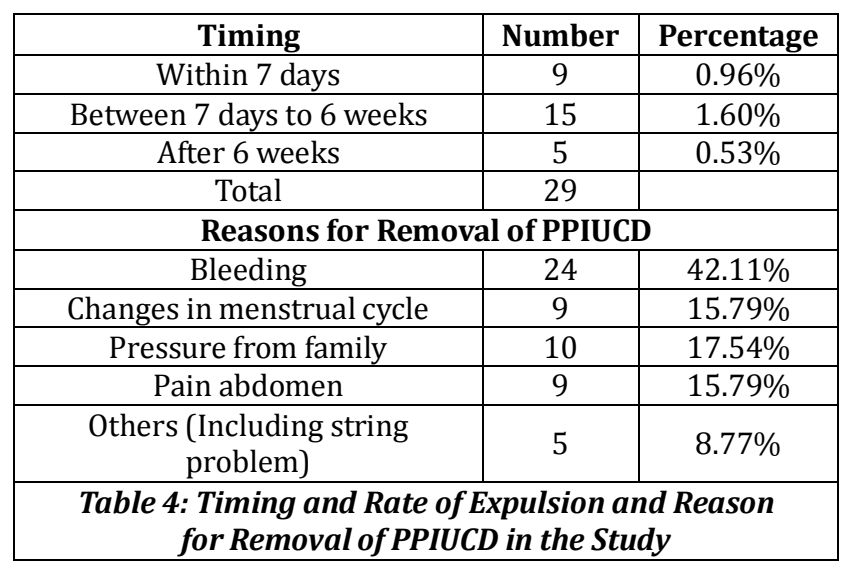

\begin{tabular}{|c|c|c|}
\hline $\begin{array}{c}\text { Continuation } \\
\text { Rate }\end{array}$ & Number & Percentage \\
\hline Total insertion & 1217 & 3.09 \\
\hline Total followup & 939 & 6.07 \\
\hline Expulsion & 29 & 90.84 \\
\hline Removal & 57 & $0.11 \%$ \\
\hline Continuation & 853 & Failure Rate of PPIUCD \\
\hline \multicolumn{3}{|c|}{ (Pregnancy with PPIUCD in-situ) } \\
in the study \\
\hline \multicolumn{3}{|c|}{ Mode of Delivery } \\
\hline Post placental & 1 & 0 \\
\hline Intra c/s & Table 5: Continuation Rate and Failure \\
Rate of PPIUCD in the Study \\
\hline
\end{tabular}

\section{CONCLUSION}

To conclude, our study found a good acceptance of PPIUCD among patients attending labour room for delivery. The acceptance was higher in patients undergoing caesarean section, which has its own vivid advantages in terms of birth spacing, regaining the parturient's health, both physical and mental. Immediate post-partum insertion of IUD appears to be safe and effective method of contraception. In spite of complications, only 57 patients had removal of IUCD. There was no case of uterine perforation. The method may be particularly beneficial in our setting, where woman do not come for postnatal contraception counselling and usage. Strategies to improve current scenario: Government needs to develop strategies to increase public awareness of the PPIUCD through different media sources. It is also important to arrange for training on PPIUCD in order to increase knowledge and skills among healthcare providers. This will also further promote PPIUCD use and aid in reduction of the expulsion rates.

\section{REFERENCES}

1. Nelson A. Gynaecology and obstericsin: intrauterine contraceptives, Philadelpia: lippincott Williams and Wilkins 2004;6.

2. Postpartum IUCD Reference Manual, New Delhi. Family Planning Division: Ministry of Health and Family Welfare, Govt of India Nov 2010.

3. Chaurasia AR. Contraceptive use in India: a data mining approach. International Journal of Population Research 2014;(2014). Article ID 821436,110. http://dx.doi.org/10.1155/2014/821436.

4. Cleland J, Bernstein S, Ezeh A, et al. Family planning: the unfinished agenda. Lancet 2006;368(9549):1810-27.

5. Shukla M, Qureshi S, Chandrawati. Post-placental intrauterine device insertion-a five year experience at a tertiary care centre in north India. Indian J Med Res 2012;136(3):432-5.

6. Maternal and Child Health Integrated Program and PPFP activities, WHO report, Washington, DC 2011.

http://www.k4health.org/sites/default/files/PPFPMeetin g Report-formatted.pdf.

7. New York Times, Health Guide, March 10, 2016. http://www.nytimes.com/health/guides/specialtopic/bir th-control-and-family-planning/intrauterine-devices(iuds).html. 
8. Katheit G, Agarwal J. Evaluation of post placental intrauterine contraceptive device (PPIUCD) in terms of awareness, acceptance and expulsion in a tertiary care centre. International journal of Reproduction, Contraception Obstetrics and Gynaecology 2013;2(4):539-43.

9. Mishra S. Evaluation of safety, efficacy, and expulsion of post-placental and intra-cesarean insertion of intrauterine contraceptive devices (PPIUCD). J Obstet Gynaecol India 2014;64(5):337-43.

10. Maluchuru S, Aruna V, Prabhavathi N. Post partum intrauterine device insertion-2 years experience at tertiary care center in Guntur medical college/govt general hospital, Guntur. Journal of dental and medical sciences 2015;14(3):56-61.

11. Grimes DA, Lopez LM, Schulz KF, et al. Immediate postpartum insertion of intrauterine devices. Cochrane Database of Systematic Reviews 2010;5. Art No: CD003036. DOI:10.1002/14651858.CD003036.

12. Borthakur S, Sarma AK, Alakananda, et al. Acceptance of post partum intra-uterine contraceptive device (ppiucd) among women attending gauhati medical college and hospital (gmch) for delivery between january 2011 to december 2014 and their follow up. Journal of Evolution of Medical and Dental Sciences 2015;4(92):15756-8.
13. Goswami G, Yadav K, Patel A. A prospective study to evaluate safety, efficacy and expulsion rate of post placental insertion of intra uterine device. Journal of Evolution of Medical and Dental Sciences 2015;4(56):9770-74.

14. Gautam R, Arya KN, Kharakwal S, et al. Over view of immediate PPIUCD application in Bundelk hand region. J Evol Med Dent Sci 2014;3(36):9518-26.

15. Vidyarama R, Nagamani T, Prasad K. Ppiucd as a long acting reversible contraceptive (larc)-an experience at a tertiary care centre. International Journal of Scientific Research 2015;4(5):5-7.

16. Jairaj S, Dayyala S. A cross sectional study on acceptability and safety of IUCD among postpartum mothers at tertiary care hospital, Telangana. Journal of clinical and diagnostic research 2016;10(1):LC01-LC04.

17. Kanhere AV, Pateriya P, Jain M. Acceptability and feasibility of immediate postpartum IUCD insertion in a tertiary care centre in central India. Int J Reprod Contracept Obstet Gynaecol 2015;4(1):179-84. 